\title{
04
}

\section{Revista PH y la Asociación de Archiveros de Andalucía: vidas paralelas}

\author{
Mateo Páez García \\ Presidente de la Asociación \\ de Archiveros de Andalucía
}

No he podido sustraerme a la tentación de parafrasear el célebre título de Plutarco y contemplar la conmemoración del vigésimoquinto aniversario de la revista $\mathrm{PH}$ y el casi coincidente de la Asociación de Archiveros de Andalucía como un caminar juntos. Aunque, en realidad, esas vidas no son paralelas: la trayectoria compartida ha confluido y se ha trenzado en muchas ocasiones. Desde los primeros números de la revista, la asociación encontró en sus páginas un acomodo en el que se sentía - y se siente-como en casa, fruto de la relación entre ambas entidades.

\section{Desde la Asociación contemplamos esta} trayectoria común con agradecimiento. No solo por la presencia y el reconocimiento en sus páginas de un quehacer profesional que es nuestra seña de identidad, sino por la pura defensa de nuestro patrimonio documental, una de las finalidades de la Asociación tal como se recoge en sus estatutos. A algunos puede parecerles extraño que la presencia de documentos y archivos en $\mathrm{PH}$ vaya mucho más allá de aquello que tenga relación con la restauración de soportes o con el estudio de sus causas de degradación. Ya la pionera Ley 3/1984, de 9 de enero, de Archivos - que se adelanta un año a la Ley estatal sobre patrimonio histórico de la etapa democrática-, había dejado meridianamente claro que los documentos de titularidad pública son patrimonio documental por origen y no por antigüedad. Y desde $\mathrm{PH}$ se apostó desde el principio por una perspectiva abierta e inclusiva que considera cuestiones patrimoniales asuntos tales como la identificación y valoración documental, la descripción archivística, los metadatos, los datos abiertos o el big data. Ninguna cuestión relacionada con los documentos o con los archivos le ha resultado ajena ni al Instituto ni a PH como su instrumento de expresión, difusión y confrontación de ideas.

Si hacemos un repaso por lo que ha supuesto en estos 25 años el asociacionismo profesional archivístico en el ámbito de nuestra Comunidad Autónoma, hay tanto luces como sombras. Mantenerse en la brecha durante estos 25 años es ya un primer motivo de satisfacción, aunque hayamos pasado por etapas oscuras difíciles de olvidar. También hay que destacar que seamos la única entidad asociativa de nuestro sector, lo que contribuye a la fortaleza del modelo representativo y posiciona a la Asociación como interlocutor privilegiado ante las administraciones y ante otros colectivos profesionales, permitiendo que haya una sola voz y evitando la presencia de mensajes contradictorios. De ahí la necesaria y fructífera presencia de la Asociación en la tramitación de normas como los dos reglamentos del Sistema Archivístico de Andalucía, o como la Ley 7/2011, de 3 de noviembre, de Documentos, Archivos y Patrimonio Documental de Andalucía, no solo por las aportaciones realizadas durante la fase de información pública, sino también por la comparecencia en sede parlamentaria. También han sido abundantes las aportaciones de la Asociación a numerosas normas técnicas, e igualmente ha de destacarse su presencia en el CTN050/SC01 "Gestión de Documentos y Aplicaciones", de AENOR. 


"Desde $P H$ se apostó
desde el principio por
una perspectiva abierta
e inclusiva que considera
cuestiones patrimoniales
asuntos tales como
la identificación y
valoración documental,
la descripción
archivística, los
metadatos, los datos
abiertos o el big data"

Mención especial merece el hecho de que en el Consejo Consultivo de la Transparencia y Protección de Datos de Andalucía esté presente, desde la constitución de este órgano colegiado, el presidente de la Asociación como persona experta en la materia, recogiéndose así una largamente ansiada aspiración de nuestro colectivo a ser reconocidos como profesionales garantes del acceso a los documentos y a la información y, por tanto, como actores imprescindibles en la transparencia de las administraciones públicas.

También se cuentan en el haber de la Asociación las múltiples actividades realizadas en estos 25 años, desde cursos de formación y conferencias hasta jornadas y congresos internacionales, muchas de ellas impulsadas en fructífera colaboración con diversas administraciones públicas, y en particular con la dirección general competente en materia de archivos de la Consejería de Cultura. Ello ha permitido la presencia de personas expertas de reconocimiento internacional, y la realización de estas actividades por todo el ámbito geográfico de nuestra Comunidad Autónoma, tratando de vencer en la medida de lo posible un nuevo centralismo.
Todo lo logrado no nos hace caer en el triunfalismo, ni muchísimo menos. El principal obstáculo de nuestra asociación es la escasa participación de las personas integradas en el movimiento asociativo. Un indicador elocuentísimo de esta situación, a veces descorazonadora, es que en algunas asambleas anuales no se ha logrado ni siquiera la presencia de la junta directiva al completo. El trabajo se desarrolla, por tanto, a base del voluntarismo y del esfuerzo denodado de las personas que integran la junta directiva, restando tiempo a su vida personal. No es un problema exclusivo de nuestra Asociación. Otras potentes asociaciones del sector en España se apoyan en un departamento universitario que dinamiza y permite la existencia de una infraestructura vigorosa en la que las personas asociadas participan y se implican. Es paradójico que cuando, por un lado, se ven reconocidas y recogidas muchas viejas reivindicaciones y aspiraciones profesionales, como las que hemos repasado, por otro lado, esté ausente un activismo profesional que nunca deja de ser necesario, y que quizá hoy lo es más que nunca. Ese es el principal reto al que nos enfrentamos hoy día, aunque sabemos que siempre contaremos con la revista $\mathrm{PH}$ como lugar de debate y punto de encuentro con otros profesionales del patrimonio.

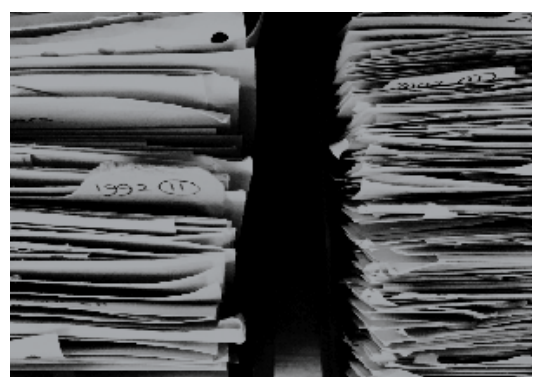

Abultado trabajo de los archivos de gestión. Fuente https://pixabay.com/ 